\title{
BMJ Open The role of concomitant ligament injury in the development of post-traumatic osteoarthritis after distal radius fractures: a protocol for a systematic review
}

\author{
Malou E Slichter (D , ${ }^{1}$ Gerald A Kraan, ${ }^{1}$ Wichor M Bramer, ${ }^{2}$ Joost W Colaris, ${ }^{3}$ \\ Nina M C Mathijssen ${ }^{1}$
}

To cite: Slichter ME, Kraan GA, Bramer WM, et al. The role of concomitant ligament injury in the development of post-traumatic osteoarthritis after distal radius fractures: a protocol for a systematic review. BMJ Open 2020;10:e039591. doi:10.1136/ bmjopen-2020-039591

- Prepublication history and additional materials for this paper is available online. To view these files, please visit the journal online (http://dx.doi org/10.1136/bmjopen-2020039591).

Received 20 April 2020 Revised 07 September 2020 Accepted 22 September 2020

Check for updates

(c) Author(s) (or their employer(s)) 2020. Re-use permitted under CC BY-NC. No commercial re-use. See rights and permissions. Published by BMJ.

${ }^{1}$ Department of Orthopaedic Surgery, Reinier de Graaf Hospital, Delft, The Netherlands ${ }^{2}$ Medical Library, Erasmus Medical Center, Rotterdam, The Netherlands

${ }^{3}$ Department of Orthopaedic Surgery, Erasmus Medical Center, Rotterdam, The Netherlands

Correspondence to Malou E Slichter; m.slichter@rdgg.nl

\section{ABSTRACT}

Introduction Treatment of distal radius fractures (DRFs) aims to restore anatomic position of the fracture fragments and congruity of the articular surface to optimise functional outcomes and prevent osteoarthritis in the long term. While ligament injury of the wrist is often associated with DRFs and sole ligament injuries of the wrist lead to osteoarthritis, it is plausible that concomitant ligament injury in DRFs may aggravate degenerative changes of the wrist. The relationship between concomitant ligament injury and post-traumatic osteoarthritis in patients with DRFs is unclear. This study aims to identify the types of associated ligament injury in patients with a DRF and to elucidate the association of ligament injury on the development of post-traumatic osteoarthritis.

Methods and analysis This protocol is written in accordance with the Preferred Reporting Items for Systematic Review and Meta-Analysis Protocol (PRISMA-P) guidelines. An electronic search in MEDLINE, Embase, Web of Science, Cochrane Central Register of Trials and Google Scholar has been created and performed by a Health Sciences librarian with expertise in systematic review searching. Original research articles in English literature, which report on concomitant ligament injury of the wrist in relation to post-traumatic osteoarthritis, patient-reported outcome measures or clinician-reported outcome measures in patients (aged $\geq 18$ years) with DRFs will be included. Two reviewers will independently screen and appraise articles and perform data extraction. In case of any disagreements, a third reviewer will be consulted. A systematic qualitative synthesis will be performed using text and tables.

Ethics and dissemination No ethical approval is required, since this is a protocol for a systematic review. The systematic review will be submitted for publication in a peer-reviewed scientific journal and for presentation at relevant conferences.

PROSPERO registration number CRD42020165007.

\section{INTRODUCTION}

Despite treatment, distal radius fractures (DRFs) often lead to incongruency of the

\section{Strengths and limitations of this study}

- This study will be the first to systematically evaluate the relationship between concomitant ligament injury of the wrist and the development of posttraumatic osteoarthritis in patients with distal radius fractures.

- A broad approach is used to answer the aetiological research question. This may cause considerable heterogeneity of the included studies, making comparison between studies difficult.

- Study screening, data extraction and quality assessment will be performed by two independent reviewers

- This protocol is written in accordance with the guidelines of Preferred Reporting Items for Systematic Review and Meta-Analysis Protocols.

articular surface of the radiocarpal joint which results in post-traumatic osteoarthritis. ${ }^{1}$

The incidence of post-traumatic osteoarthritis after DRFs highly varies in literature, because of heterogeneity of the studies regarding the type of DRF, follow-up duration, and the used diagnostics for assessing post-traumatic osteoarthritis. ${ }^{2-7}$ The reported overall prevalence of post-traumatic osteoarthritis after intra-articular DRFs ranges from $37 \%$ to $50 \%{ }^{1}$

The pathogenesis of post-traumatic osteoarthritis is likely multifactorial. Some studies postulate that it is associated with direct damage to cartilage and/or bone during trauma, as well as chronic joint overload secondary to residual articular incongruity or malalignment, or articular instability due to soft tissue injury. The relative contribution and importance of these factors in developing post-traumatic osteoarthritis is 
unknown..$^{8-10}$ Both are extensively studied separately in literature.

Incongruity of the articular surface caused by a step-off or gap has been shown to be a predictor for the development of post-traumatic osteoarthritis in DRFs, while other radiological factors, such as shortened radial length, dorsal angulation, radial inclination, ulnar variance and anteroposterior distance show conflicting results. ${ }^{1}$ Failure to anatomically reduce fracture fragments can accelerate this degenerative process ${ }^{12411-13}$ and may compromise functional outcome. ${ }^{14}$

In addition, DRFs are often associated with multiple types of ligament injuries of the wrist. In up to $75 \%$ of DRFs soft tissue injury was reported. ${ }^{15-29}$ If not diagnosed and treated correctly, additional lesions of the carpal ligaments can cause wrist disorders. The presence and extent of these soft tissue injuries in DRFs may provide a potential explanation for the variable outcomes seen after treatment of DRFs.

As is known, sole ligament injury of the wrist in the absence of a fracture, in particular scapholunate (SL) ligament injury in combination with injury to the secondary stabilisers, ${ }^{30}$ may lead to a change in the carpal kinematics, instability, chronic wrist pain and possibly secondary degenerative changes. ${ }^{31}{ }^{32}$ The natural course of chronic isolated SL ligament injury is unclear and multiple studies show different results in the long term regarding the incidence of degenerative arthritic changes and decreased wrist function after isolated SL ligament injury. ${ }^{33-35}$ However, current concepts are to restore ligament continuity and carpal kinematics within 4-6 weeks to produce a painless and stable wrist to prevent chronic instability and osteoarthritis in the long term..$^{30} 3536$

Even though instability and incongruity often coexist after intra-articular fractures and both may exacerbate chronic cartilage loading, ${ }^{9}$ the primary focus of treatment of DRFs is to restore the anatomical position and congruity of the articular surface. The evaluation of ligament injury is not performed standardly. If instability is a potent determinant of post-traumatic osteoarthritis, the physician should ensure both joint stability and joint congruity. ${ }^{9}$

Therefore, the primary aim of this systematic review is to identify the types of associated ligament injury in patients with a DRF and to elucidate the association of ligament injury on developing post-traumatic osteoarthritis. This allows for more understanding of the pathomechanics of secondary osteoarthritis in DRFs.

\section{Objectives}

1. To determine the incidence and types of concomitant ligament injury in DRFs.

2. To assess the difference in the incidence of posttraumatic osteoarthritis in patients with DRFs with ligament injury compared with patients without ligament injury and whether a relationship between ligament injury and radiological degree of osteoarthritis is reported.
Table 1 Inclusion and exclusion criteria for the studies

\begin{tabular}{|c|c|c|}
\hline & Inclusion criteria & Exclusion criteria \\
\hline Study design & $\begin{array}{l}\text { (pseudo-)RCTs } \\
\text { Cohort studies } \\
\text { Case-control } \\
\text { studies } \\
\text { Case series }>5 \\
\text { patients }\end{array}$ & $\begin{array}{l}\text { Case series } \leq 5 \\
\text { patients } \\
\text { Case-reports } \\
\text { Commentaries } \\
\text { Editorials } \\
\text { Letters } \\
\text { Conference abstracts } \\
\text { Book chapters }\end{array}$ \\
\hline Participants & $\begin{array}{l}\text { Patients with all } \\
\text { types of DRFs } \\
\text { Aged } \geq 18 \text { years }\end{array}$ & $\begin{array}{l}\text { Animal or cadaveric } \\
\text { studies } \\
\text { Aged }<18 \text { years }\end{array}$ \\
\hline $\begin{array}{l}\text { Report } \\
\text { characteristics }\end{array}$ & $\begin{array}{l}\text { Concomitant } \\
\text { ligament injury* } \\
\text { in relation to } \\
\text { post-traumatic } \\
\text { osteoarthritis, } \\
\text { PROMs or CROMs }\end{array}$ & $\begin{array}{l}\text { TFCC injury } \\
\text { DRUJ injury }\end{array}$ \\
\hline Language & English language & Other language \\
\hline
\end{tabular}

*See online supplemental file 2 for a list of all included injuries and ligaments.

CROM, clinician-reported outcome measure; DRF, distal radius fracture; DRUJ, distal radioulnar joint; PROM, patient-reported outcome measure; RCT, randomised controlled trial; TFCC, triangular fibrocartilage complex.

3. To assess the difference in patient-reported outcome measures (PROMs) and clinician-reported outcome measures (CROMs) in patients with DRFs with ligament injury compared with patients without ligament injury.

\section{METHODS AND ANALYSIS}

The systematic review protocol is registered with the International Prospective Register of Systematic Reviews (PROSPERO) (CRD42020165007) at https://www.crd. york.ac.uk/PROSPERO/\#myprospero. This protocol is written in accordance with the guidelines of Preferred Reporting Items for Systematic Review and Meta-Analysis Protocols (PRISMA-P). The PRISMA-P checklist can be found in online supplemental file $1 .^{37} 38$

\section{Eligibility criteria}

See table 1 for an overview of the inclusion and exclusion criteria.

\section{Study designs}

Randomised controlled trials (RCTs), pseudo-RCTs and non-randomised studies, including cohort studies and casecontrol studies will be included. Prospective and retrospective studies will be included. Case series with a population of $\leq 5$ patients, case-reports, commentaries, editorials, letters, conference abstracts and book chapters will be excluded.

\section{Participants}

Studies with patients, aged $\geq 18$ years, with DRFs will be included. Both intra-articular and extra-articular DRFs 
Table 2 Diagnosis of concomitant ligament injury of the wrist

\begin{tabular}{|c|c|c|c|}
\hline & $\begin{array}{l}\text { All ligament injury and } \\
\text { carpal instabilities }\end{array}$ & SL ligament injury & LT ligament injury ${ }^{55}$ \\
\hline \multirow[t]{3}{*}{$\begin{array}{l}\text { Physical } \\
\text { examination }\end{array}$} & \multirow[t]{3}{*}{$\begin{array}{l}\text { No specific } \\
\text { requirements. }\end{array}$} & $\begin{array}{l}\text { Watson's scaphoid shift test-elicits } \\
\text { a palpable and/or audible reduction } \\
\text { of the subluxated scaphoid and elicits } \\
\text { symptomatic pain, usually on the dorsal } \\
\text { side. }^{56}\end{array}$ & $\begin{array}{l}\text { Ulnar snuffbox test-elicits pain when } \\
\text { performing lateral pressure on the triquetrum } \\
\text { between the flexor carpi ulnaris and extensor } \\
\text { carpi ulnaris tendons. }\end{array}$ \\
\hline & & \multirow[t]{2}{*}{$\begin{array}{l}\text { Finger extension test-elicits pain when } \\
\text { performing maximum finger extension } \\
\text { against resistance during simultaneous } \\
\text { volar flexion of the wrist. }\end{array}$} & $\begin{array}{l}\text { Shear test-laxity compared with the } \\
\text { contralateral side or elicitation of recognisable } \\
\text { symptoms when performing a dorsal force on } \\
\text { the triquetrum/pisiform and volar force on the } \\
\text { lunate. }\end{array}$ \\
\hline & & & $\begin{array}{l}\text { LT ballottement test-elicits pain when rocking } \\
\text { the triquetrum back and forth on the stabilised } \\
\text { lunate. }\end{array}$ \\
\hline \multirow{3}{*}{ X-ray } & \multirow{3}{*}{$\begin{array}{l}\text { No specific } \\
\text { requirements. }\end{array}$} & SL angle of $>60^{\circ}$ on lateral view. & - SL angle of $<30^{\circ}$ on lateral view. \\
\hline & & $\begin{array}{l}\text { CL angle of }>30^{\circ} \text { on lateral view (taking } \\
\text { into account the SL angle). }\end{array}$ & $\begin{array}{l}\text { CL angle of }>30^{\circ} \text { on lateral view (taking in to } \\
\text { account the } S L \text { angle). }\end{array}$ \\
\hline & & $\begin{array}{l}\text { Exaggerated cortical ring of the distal } \\
\text { scaphoid on PA view. }\end{array}$ & \\
\hline $\begin{array}{l}\text { MRI scan, CT } \\
\text { scan, fluoroscopy, } \\
\text { cinematography, } \\
\text { other }^{57}\end{array}$ & $\begin{array}{l}\text { No specific } \\
\text { requirements. }\end{array}$ & No specific requirements. & No specific requirements. \\
\hline Arthroscopy & Geissler classification ${ }^{15}$ & ther relevant classification. & \\
\hline
\end{tabular}

$\mathrm{CL}$, capitolunate; LT, lunotriquetral; PA, posteroanterior; SL, scapholunate.

will be eligible. Animal studies or cadaveric studies will be excluded.

\section{Exposure}

Patients with a DRF and concomitant ligament injury of the wrist are eligible. Lesions of the triangular fibrocartilage complex and the distal radioulnar joint are not included, since these are a separate entity in DRFs. See online supplemental file 2 for a list of all included injuries and ligaments.

Ligament injury of the wrist must be diagnosed by history, physical examination, radiology or arthroscopy or other relevant diagnostics as stated by the article. See table 2 for details on the diagnosis of ligament injury and carpal instabilities.

\section{Comparator}

Patients with DRFs without ligament injury.

\section{Outcomes}

Outcomes are incidence or prevalence of post-traumatic osteoarthritis or an association, correlation or regression between post-traumatic osteoarthritis and ligament injury. Post-traumatic osteoarthritis must be assessed on X-ray, CT scan or MRI scan of the wrist. All classification systems for osteoarthritis will be eligible, such as the Kellgren and Lawrence classification, ${ }^{39}$ Scapholunate Advanced
Collapse classification, ${ }^{40}$ Knirk and Jupiter classification ${ }^{4}$ or other relevant classification as stated by the article.

Other outcomes are functional outcomes, such as PROMs and CROMs (eg, grip strength and range of motion).

See online supplemental file 2 for the exact PECO research question with a list of all search terms.

\section{Setting and time frame}

Studies will need a minimum length of 1 year of follow-up after trauma to assess post-traumatic osteoarthritis. However, studies with a shorter period of follow-up will be included, because otherwise relevant studies for determining the incidence of concomitant ligamentous injury might be missed. In addition, it is expected that only a few studies evaluate the exposure versus the comparator. Therefore, the comparator will not be used as an inclusion criterion during our selection process.

\section{Report characteristics}

Only published data in English will be included. A list of possible relevant titles in other languages will be provided as an appendix. There will be no limitation on the year in which the study was performed or published. Only full text articles will be included. 


\section{Search strategy}

An electronic search in MEDLINE ALL via Ovid, Embase via Embase.com, Web of Science Core Collection, Cochrane Central Register of Trials via Wiley and Google Scholar has been created and performed on 24 October 2019 by a Health Sciences librarian with expertise in systematic review searching (WMB). The initial list of relevant search terms used during the preparation of the search strategy was drawn up by a senior hand surgeon (GAK), orthopaedic researcher (NMCM) and medical doctor (MES). Animal studies, conference abstracts, case reports, book chapters and dissertation abstracts were excluded from the MEDLINE and Embase search strategies. The search strategies of the databases are included in online supplemental file 3.

The reviewers searched PROSPERO and existing databases for any ongoing or existing systematic review on this topic prior to writing this protocol. No such review has been identified.

The search will be updated towards the end of the review to retrieve the most recent eligible studies. Reference lists of the included studies and relevant reviews will be screened to identify additional potentially eligible studies which are not identified in the electronic searches.

\section{Study records}

Selection process

Literature search results will be uploaded to Endnote. ${ }^{41}$ Duplicate records of the same report will be removed from the results. ${ }^{42}$ Two reviewers (MES and EMS) will independently screen the title and abstracts for potential relevancy.

Relevant full text articles will be uploaded to the Covidence website, where the review will be managed. ${ }^{43}$ This is an internet based software programme that facilitates collaboration among reviewers during the study selection process. The two independent reviewers will screen the full text articles using a standardised form based on the eligibility criteria. This form will be piloted on the 10 most recent citations prior to the selection process. Multiple reports of the same study will be linked.

The reason for exclusion will be recorded for articles that do report on ligament injury in patients with DRFs but do not meet the inclusion criteria. The search and selection process will be presented in study flow diagram according to the PRISMA statement. ${ }^{44}$

\section{Data management and collection}

To minimise errors and reduce potential biases, data will be extracted by the two independent reviewers onto piloted, standardised data collection forms designed for this study on the Covidence website. ${ }^{43}$

\section{Data items}

Patient characteristics (eg, age, sex), fracture characteristics (eg, intra-articular versus extra-articular, type of DRF), treatment, incidence or prevalence of osteoarthritis, degree of osteoarthritis, PROMs, grip strength, range of motion, incidence or prevalence of concomitant ligament injury, type and grade of ligament injury and how it was diagnosed will be extracted. In addition, study characteristics (ie, trial design, trial size, primary and secondary outcomes of the study, duration of follow-up, source of financial support) and information for quality assessment will be extracted.

\section{Outcomes and prioritisation}

The primary outcome of the systematic review is an association or correlation between osteoarthritis and concomitant ligament injury after DRFs. If no association or correlation is reported, the incidence or prevalence of osteoarthritis in relation to concomitant ligament injury will be reported. Outcomes will be subdivided for different types of DRFs and different intervention groups where appropriate. If studies vary at different time points, the incidence and prevalence of osteoarthritis will be subdivided as follows:

- Early onset of osteoarthritis, 1-2 years after trauma.

- Middle late onset of osteoarthritis, 2-5 years after trauma.

- Late onset of osteoarthritis, over 5 years after trauma. Secondary outcomes of the systematic review will be PROMs, such as the Patient-Reported Wrist Evaluation (PRWE) ${ }^{45}$ (Quick) Disabilities of Arm Shoulder and Hand ([Quick]DASH) ${ }^{46}$ Michigan Hand Outcome Questionnaire $(\mathrm{MH}[\mathrm{O}] \mathrm{Q}),{ }^{47}$ the Australian Canadian Osteoarthritis index (AUSCAN) ${ }^{48}$ Visual Analogue Scale (VAS) or numeric rating scale (NRS) for pain or other PROM as reported by the study. Other secondary outcomes of the systematic review are CROMs, such as grip strength and range of motion.

Outcomes will be presented for the latest evaluated time points according to the study.

\section{Risk of bias in individual studies}

The two independent reviewers will assess the risk of bias for each included study.

The Cochrane Collaboration's Risk of Bias tool 2.0 (RoB 2.0) will be used for RCTs. ${ }^{49}$ The Risk Of Bias In NonRandomized Studies-of Interventions (ROBINS-I) will be used for non-randomised studies or quasirandomised studies. ${ }^{50}$ The Newcastle-Ottawa Scale (NOS) will be used for quality assessment of prospective and retrospective cohort studies, which do not compare interventions, as well as for case-control studies and small case-series. ${ }^{51}$ The NOS will be adapted to meet the specific needs of this systematic review.

Discrepancies between the independent reviewers will be clarified through discussion after every step of the selection process, data extraction process and the risk of bias assessment. A third reviewer (GAK) will be consulted if no consensus is achieved. Furthermore, authors will be contacted if more information is needed to make final decisions on the inclusion of studies (ie, clarification of study eligibility), and if data are unclear or missing from reports. 


\section{Data synthesis}

Since the research question is aetiological and broader in nature, a systematic, narrative, qualitative summary will be performed according to the PRISMA statement, to explore the findings and relationship between ligament injury and the incidence of osteoarthritis within studies and between the included studies. ${ }^{44}$ Studies which are eligible based on patient, exposure and outcomes will be described. These studies do report on concomitant ligament injury in patients with DRF but do not compare their results to patients with DRF without ligament injury. If it turns out that $\geq 5$ studies are eligible in terms of exposure and comparator, the systematic review will be based on these studies only. Hence, the systematic review will be based on studies with a comparator and higher overall quality.

Information will be presented in the text and tables to summarise and explain the characteristics and findings of the included studies. A table of summary will first be sorted on studies that compare both groups of patients with and without ligament injury in relation to post-traumatic osteoarthritis and functional outcomes and subsequently the studies that did not report on both groups. Second, it will be sorted on type of study design and will be graded from low risk of bias to high risk of bias within type of study design. In addition, a risk of bias table will be presented. All studies which are included will be reported, regardless of the risk of bias. However, low risk of bias studies will be emphasised in the qualitative summary.

No meta-analysis will be performed since we expect heterogeneity of the studies. Thus, a quantitative synthesis may not be appropriate.

\section{Meta-bias}

Assessment of meta-bias will not be performed.

\section{Confidence in cumulative evidence}

Not applicable.

\section{Patient and public involvement}

No patients are involved during this study.

\section{ETHICS AND DISSEMINATION}

No ethical approval is required, since this is a protocol for a systematic review. The systematic review will be submitted for publication in a peer-reviewed scientific journal and for presentation at relevant conferences.

\section{DISCUSSION}

Aims of this systematic review are to summarise existing literature on the effect of concomitant ligament injury in adult patients with DRFs on the incidence and radiological degree of osteoarthritis, and its effect on functional outcomes, as well as to identify any existing gaps in knowledge. To our knowledge, no systematic review in English literature has reported on the incidence of post-traumatic osteoarthritis and clinical outcomes of patients with DRFs without ligament injury compared with those with ligament injury on the long term. Two (systematic) reviews have been performed on the use of wrist arthroscopy in the management of DRFs. These mainly focus on the indications and additional value of wrist arthroscopy in DRFs in terms of functional outcomes and radiological osteoarthritis. Part of these reviews entails concomitant ligament injury seen during arthroscopy; however, no association was reported on the type and grade of ligamentous injuries and radiological degree of osteoarthritis. Also, the authors did not compare outcomes between patients with isolated DRFs and patients with DRFs with concomitant ligament injury. ${ }^{52} 53$ Likewise, Fowler performed a non-systematic review on SL and lunotriquetral ligament injuries associated with acute DRFs. The effect on the development of post-traumatic osteoarthritis was not addressed in this article. ${ }^{54}$

It is possible that none of the eligible studies address our primary research question and only briefly report on osteoarthritis. Therefore, a broad approach to our synthesis was set up. Realistically, this may result in substantial heterogeneity of the studies in terms of study design, types of DRFs and their treatment, how ligament injury was assessed and what classification is used and outcomes assessed at different time points. Therefore, no meta-analysis will be performed. Findings of this review could clarify the role and relevance of concomitant ligament injury of the wrist on the development of post-traumatic osteoarthritis in patients with DRFs and whether this topic needs to be addressed in future studies on management of preventing post-traumatic osteoarthritis of the wrist after DRFs.

Acknowledgements We would like to thank the scientific activities committee (WAC) of the Reinier de Graaf Hospital for providing financial support with respect to the article processing charge (APC).

Contributors MES conceived the idea of the study, contributed to the development of the selection criteria, the risk of bias assessment strategy and data extraction criteria, drafted the manuscript of the protocol, will perform the selection process and data collection as an independent reviewer, and will draft the manuscript of the systematic review. GAK provided expertise on osteoarthritis of hand and wrist, contributed to the development of the selection criteria, the risk of bias assessment strategy, data extraction criteria and is the third reviewer in case of any disagreements during the selection and data extraction process. WMB developed the search strategy and provided expertise on the methodology. JWC provided expertise on osteoarthritis of hand and wrist, contributed to the development of the selection criteria, the risk of bias assessment strategy and data extraction criteria. NMCM contributed to the development of the selection criteria, the risk of bias assessment strategy and data extraction criteria. All authors read and approved the final manuscript.

Funding The authors have not declared a specific grant for this research from any funding agency in the public, commercial or not-for-profit sectors.

Competing interests None declared.

Patient consent for publication Not required.

Provenance and peer review Not commissioned; externally peer reviewed.

Supplemental material This content has been supplied by the author(s). It has not been vetted by BMJ Publishing Group Limited (BMJ) and may not have been peer-reviewed. Any opinions or recommendations discussed are solely those of the author(s) and are not endorsed by BMJ. BMJ disclaims all liability and responsibility arising from any reliance placed on the content. Where the content 
includes any translated material, BMJ does not warrant the accuracy and reliability of the translations (including but not limited to local regulations, clinical guidelines, terminology, drug names and drug dosages), and is not responsible for any error and/or omissions arising from translation and adaptation or otherwise.

Open access This is an open access article distributed in accordance with the Creative Commons Attribution Non Commercial (CC BY-NC 4.0) license, which permits others to distribute, remix, adapt, build upon this work non-commercially, and license their derivative works on different terms, provided the original work is properly cited, appropriate credit is given, any changes made indicated, and the use is non-commercial. See: http://creativecommons.org/licenses/by-nc/4.0/.

\section{ORCID iD}

Malou E Slichter http://orcid.org/0000-0002-7085-8622

\section{REFERENCES}

1 Lameijer CM, ten Duis HJ, Dusseldorp Ivan, et al. Prevalence of posttraumatic arthritis and the association with outcome measures following distal radius fractures in non-osteoporotic patients: a systematic review. Arch Orthop Trauma Surg 2017;137:1499-513.

2 Lutz M, Arora R, Krappinger D, et al. Arthritis predicting factors in distal intraarticular radius fractures. Arch Orthop Trauma Surg 2011;131:1121-6.

3 Forward DP, Davis TRC, Sithole JS. Do young patients with malunited fractures of the distal radius inevitably develop symptomatic post-traumatic osteoarthritis? J Bone Joint Surg $\mathrm{Br}$ 2008;90-B:629-37.

4 Knirk JL, Jupiter JB. Intra-articular fractures of the distal end of the radius in young adults. $J$ Bone Joint Surg Am

1986;68:647-59.

5 Goldfarb CA, Rudzki JR, Catalano LW, et al. Fifteen-year outcome of displaced intra-articular fractures of the distal radius. J Hand Surg Am 2006;31:633-9.

6 Catalano LW, Cole RJ, Gelberman RH, et al. Displaced intra-articular fractures of the distal aspect of the radius. long-term results in young adults after open reduction and internal fixation. $J$ Bone Joint Surg Am 1997;79:1290-302.

7 Young BT, Rayan GM. Outcome following nonoperative treatment of displaced distal radius fractures in low-demand patients older than 60 years. J Hand Surg Am 2000;25:19-28.

8 Giannoudis PV, Tzioupis C, Papathanassopoulos A, et al. Articular step-off and risk of post-traumatic osteoarthritis. Evidence today. Injury 2010;41:986-95.

9 McKinley TO, Rudert MJ, Koos DC, et al. Incongruity versus instability in the etiology of posttraumatic arthritis. Clin Orthop Relat Res 2004;423:44-51

10 Schenker ML, Mauck RL, Ahn J, et al. Pathogenesis and prevention of posttraumatic osteoarthritis after intra-articular fracture. J Am Acad Orthop Surg 2014;22:20-8.

11 Bradway JK, Amadio PC, Cooney WP. Open reduction and internal fixation of displaced, comminuted intra-articular fractures of the distal end of the radius. J Bone Joint Surg 1989;71:839-47.

12 Kopylov P, Johnell O, Redlund-Johnell I, et al. Fractures of the distal end of the radius in young adults: a 30-year follow-up. J Hand Surg Am 1993;18:45-9.

13 Steffen T, Eugster T, Jakob RP. Twelve years follow-up of fractures of the distal radius treated with the $\mathrm{AO}$ external fixator. Injury1994;25:SD44-54

14 Trumble TE, Schmitt SR, Vedder NB. Factors affecting functional outcome of displaced intra-articular distal radius fractures. $J$ Hand Surg Am 1994;19:325-40.

15 Geissler WB, Freeland AE, Savoie FH, et al. Intracarpal soft-tissue lesions associated with an intra-articular fracture of the distal end of the radius. J Bone Joint Surg 1996;78:357-65.

16 Mrkonjic A, Lindau T, Geijer M, et al. Arthroscopically diagnosed scapholunate ligament injuries associated with distal radial fractures: a 13- to 15-year follow-up. J Hand Surg Am 2015;40:1077-82.

17 Forward DP, Lindau TR, Melsom DS. Intercarpal ligament injuries associated with fractures of the distal part of the radius. J Bone Joint Surg Am 2007;89:2334-40.

18 Stoffelen D, De Mulder K, Broos P. The clinical importance of carpal instabilities following distal radial fractures. Journal of Hand Surgery 1998;23:512-6.

19 Varitimidis SE, Basdekis GK, Dailiana ZH, et al. Treatment of intraarticular fractures of the distal radius. J Bone Joint Surg Br 2008;90B:778-85.
20 Gradl G, Pillukat T, Fuchsberger T, et al. The functional outcome of acute scapholunate ligament repair in patients with intraarticular distal radius fractures treated by internal fixation. Arch Orthop Trauma Surg 2013:133:1281-7.

21 Gunal I, Ozaksoy D, Altay T, et al. Scapholunate dissociation associated with distal radius fractures. Eur J Orthop Surg Traumatol 2013;23:877-81.

22 Kasapinova K, Kamiloski V. Influence of associated lesions of the intrinsic ligaments on distal radius fractures outcome. Arch Orthop Trauma Surg 2015;135:831-8.

23 Tang J-B, Shi D, Gu YQ, et al. Can cast immobilization successfully treat scapholunate dissociation associated with distal radius fractures? J Hand Surg Am 1996;21:583-90.

24 Lindau T, Arner M, Hagberg L. Intraarticular lesions in distal fractures of the radius in young adults. A descriptive arthroscopic study in 50 patients. J Hand Surg Br 1997;22:638-43.

25 Richards RS, Bennett JD, Roth JH, et al. Arthroscopic diagnosis of intra-articular soft tissue injuries associated with distal radial fractures. J Hand Surg Am 1997;22:772-6.

26 Spence LD, Savenor A, Nwachuku I, et al. Mri of fractures of the distal radius: comparison with conventional radiographs. Skeletal Radiol 1998;27:244-9.

27 Peicha G, Seibert F-J, Fellinger M, et al. Midterm results of arthroscopic treatment of scapholunate ligament lesions associated with intra-articular distal radius fractures. Knee Surg, Sports Traumatol, Arthros 1999;7:327-33.

28 Ruch DS, Yang CC, Smith BP. Results of acute arthroscopically repaired triangular fibrocartilage complex injuries associated with intra-articular distal radius fractures. J Arthros Related Surg 2003;19:511-6.

29 Swart E, Tang P. The effect of ligament injuries on outcomes of operatively treated distal radius fractures. Am J Orthop 2017;46:E41-6.

30 Konopka G, Chim H. Optimal management of scapholunate ligament injuries. Orthop Res Rev 2018;10:41-54.

31 Palmer AK, Dobyns JH, Linscheid RL. Management of posttraumatic instability of the wrist secondary to ligament rupture. $J$ Hand Surg Am 1978;3:507-32.

32 Chantelot C. Post-Traumatic carpal instability. Orthopaed Traumatol: Surg Res 2014;100:S45-53.

33 O'Meeghan CJ, Stuart W, Mamo V, et al. The natural history of an untreated isolated scapholunate interosseus ligament injury. J Hand Surg 2003;28:307-10.

34 Westkaemper JG, Mitsionis G, Giannakopoulos PN, et al. Wrist arthroscopy for the treatment of ligament and triangular fibrocartilage complex injuries. J Arthros Relat Surg 1998;14:479-83.

35 Montgomery SJ, Rollick NJ, Kubik JF, et al. Surgical outcomes of chronic isolated scapholunate interosseous ligament injuries: a systematic review of 805 wrists. CJS 2019;62:199-210.

36 Andersson JK. Treatment of scapholunate ligament injury: current concepts. EFORT Open Rev 2017;2:382-93.

37 Shamseer L, Moher D, Clarke M, et al. Preferred reporting items for systematic review and meta-analysis protocols (PRISMA-P) 2015 elaboration and explanation. BMJ 2015;349:97647.

38 Moher D, Shamseer L, Clarke M, et al. Preferred reporting items for systematic review and meta-analysis protocols (PRISMA-P) 2015 statement. Syst Rev 2015;4.

39 Kellgren JH, Lawrence JS. Radiological assessment of osteoarthrosis. Ann Rheum Dis 1957;16:494-502.

40 Watson HK, Ballet FL. The SLAC wrist: scapholunate advanced collapse pattern of degenerative arthritis. J Hand Surg Am 1984:9:358-65

41 Thomson Reuters. Endnote X8, 2016

42 Bramer WM, Giustini D, de Jonge GB, et al. De-duplication of database search results for systematic reviews in endnote. J Med Libr Assoc 2016;104:240-3.

43 Veritas Health Innovation. Covidence systematic review software. Available: https://www.covidence.org/home

44 Moher D, Liberati A, Tetzlaff J, et al. Preferred reporting items for systematic reviews and meta-analyses: the PRISMA statement. PLoS Med 2009;6:e1000097.

45 Mehta SP, MacDermid JC, Richardson J, et al. A systematic review of the measurement properties of the Patient-Rated wrist evaluation. $J$ Orthop Sports Phys Ther 2015;45:289-98.

46 Hudak P, Amadio P, Bombardier C. Development of an upper extremity outcome measure: the DASH (disabilities of the arm, shoulder and hand). the upper extremity Collaborative Group (UECG). Am J Ind Med 1996;29:602-8.

47 Chung KC, Pillsbury MS, Walters MR, et al. Reliability and validity testing of the Michigan hand outcomes questionnaire. J Hand Surg Am 1998;23:575-87. 
48 Bellamy N, Campbell J, Haraoui B, et al. Dimensionality and clinical importance of pain and disability in hand osteoarthritis: development of the Australian/Canadian (AUSCAN) osteoarthritis hand index. Osteoarthritis and Cartilage 2002;10:855-62.

49 Sterne JAC, Savović J, Page MJ, et al. Rob 2: a revised tool for assessing risk of bias in randomised trials. BMJ 2019;2:14898.

50 Sterne JA, Hernán MA, Reeves BC, et al. ROBINS-I: a tool for assessing risk of bias in non-randomised studies of interventions. BMJ 2016;355:i4919.

51 Wells GA, Shea B, O'Connell D, et al. The Newcastle-Ottawa scale (NOS) for assessing the quality of nonrandomised studies in meta-analyses. Available: http://www.ohri.ca/programs/clinical_ epidemiology/oxford.asp [Accessed 17 Sep 2019].
52 Smeraglia F, Del Buono A, Maffulli N. Wrist arthroscopy in the management of articular distal radius fractures. Br Med Bull 2016;119:157-65.

53 Shkolnikova J, Harvey J. Wrist arthroscopy in the management of distal radius fractures. Ann Jt 2018;3:77.

54 Fowler TP. Intercarpal ligament injuries associated with distal radius fractures. J Am Acad Orthop Surg 2019;27:e893-901.

55 Butterfield WL, Joshi AB, Lichtman D. Lunotriquetral injuries. J Am Soc Surg Hand 2002;2:195-203.

56 Watson HK, Ashmead D, Makhlouf MV, Kirk Watson H, Vincent Makhlouf M. Examination of the scaphoid. J Hand Surg Am 1988;13:657-60.

57 Sulkers GSI, Schep NWL, Maas M, et al. The diagnostic accuracy of wrist cineradiography in diagnosing scapholunate dissociation. $J$ Hand Surg Eur Vol 2014;39:263-71. 